\title{
UJI SENYAWA FLAVONOID TOTAL DARI EKSTRAK ETANOL HERBA BINARA (Artemisia Annua) MENGGUNAKAN HIGH PERFORMANCE LIQUID CHROMATOGRAPHY (HPLC) TAHUN 2019
}

\author{
Novandi Purba ${ }^{1}$ Jhon Patar Sinurat ${ }^{2}$ Romauli Anna Teresia Marbun ${ }^{3}$ \\ Fakultas Farmasi Institut Kesehatan Medistra Lubuk Pakam \\ E-mail : gultomvandi6196@gmail.com \\ DOI : https://doi.org/10.35451/jfm.v2i1.323
}

\begin{abstract}
ABSTRAK
Herba binara (Artemisia Annua) is one of the plants that contains flavonoids which are efficacious as antioxidants and anticancer. The purpose of this study was to determine the total flavonoid compounds contained in ethanol extract of binara herbs (Artemisia Annua). Compounds in ethanol extract of binara herbs were identified by phytochemical screening. The results showed that the ethanol extract of binara herbs contained alkaloids, flavonoids, saponins, and tannins. Extraction was carried out in two stages, namely maceration stage with $96 \%$ ethanol and fat removal stage by hydrolysis using distilled water solvent. The extract was partitioned with ethyl acetate and n-hexane solvents, then the partitions were examined by TLC using the mobile phase of chloroform and ethyl acetate (7: 3). Ribbon patches that have the same Rf and color prices as the initial detection are taken and searched. Then analyzed using High Performance Liquid Chromatography (HPLC). Based on the wavelength as well as the TLC test, a partial structure which was strongly suspected of total flavonoids was $0.93 \mathrm{~g}$.
\end{abstract}

Kata Kunci :Herba Binara (Artemisia Annua), flavonoid, KLT, High Performance Liquid Chromatography(HPLC).

\section{PENDAhUlUAN}

Berbagai tumbuhan di Indonesia yang dimanfaatkan secara tradisional untuk penanggulangan masalah kesehatan, salah satunya adalah Tumbuhan Herba Binara (Artemisia Annua). Artemisia Annua dari familia Asteraceae merupakan salah satu jenis Artemisia yang banyak ditemukan di Jawa Tengah khususnya di daerah Kopeng dan Tawang mangu. Jenis ini kurang banyak dieksplorasi karena kandungan artemisianya relatif rendah dibanding jenis Artemisia yang lain. Selain itu tumbuhan ini juga dikenal memiliki efek merangsang rahim sehingga dapat meningkatkan efek sehingga dapat meningkatkan efek menstruasi.Tumbuhan binara berkhasiat untuk mengobati disentri, keputihan, muntah darah, mimisan, pendarahan usus, menghilangkan rasa sakit, mencegah keguguran dan mengatur menstruasi. Survey yang dilakukan di Masyarakat Simpang Empat Kabupaten Karo, masyarakat menggunakan Herba Binara dengan cara mengunyah beberapa daun kemudian ditempelkan pada bagian luka diluar tubuh seperti luka tersayat. Pengobatan diare dan perut yang kram, herba binara diambil sebanyak 5 lembar yang telah dipanaskan diatas api dan kemudian ditempelkan disekitar perut yang sakit (Widyaningrum, 2011; Marbun, et al, 2018).

Flavonoid merupakan sekelompok besar senyawa polifenol tanaman yang 
tersebar luas dalam berbagai bahan makanan dan berbagai konsentrasi. Flavonoid memiliki kerangka dasar karbon yang terdiri atas 15 atom karbon, dimana dua cincin benzen (C6) terikat pada suatu rantai propan (C3) sehingga membentuk susunan C6-C3-C6. Flavonoid dapat berperan sebagai antibakteri dengan mengganggu fungsi dari mikroorganisme bakteri. Flavonoid menghambat pertumbuhan bakteri dengan menyebabkan terjadinya kerusakan permeabilitas dinding sel bakteri, mikrosom dan lisosom (Yunukawati, 2013).

Berdasarkan laporan penelitian yang telah dilakukan, tumbuhan binara (Artemisia Annua) mengandung senyawa bioaktif berupa flavonoid dan minyak atsiri, saponin. Dari penelitian sebelumnya, dilaporkan herba binara memiliki bahan aktif berupa flavonoid yang dapat digunakan sebagai antibakteri (Lia Febrina dkk, 2017). Berdasarkan penelitian sebelumnya, menujukkan bahwa herba binara (Artemisia Annua) mengandung flavonoid dan mempunyai aktivitas antioksidan yang sedang sampai kuat (Linta,2018). Dari penelitian sebelumnya, dilaporkan bahwa herba binara memiliki aktivitas antioksidan ekstrak daun tiga genus Artemisia sp dengan metode DPPH serta penetapan kadar flavonoid, fenol dan karotenoid (Asep, 2017).

Menurut survey literature menunjukkan bahwa konstituen bioaktif Artemisia sp, tersebut memberikan keuntungan bagi kesehatan manusia dan beberapa spesies lain telah dilaporkan memiliki aktivitas antimalaria, sitotoksik, antihepatolitik, antibakteri, antijamur dan antioksidan (Tan, et al, 1999).

Oleh karena itu, dalam penelitian ini akan dilakukan identifikasi senyawa Flavonoid Total yang terkandung pada ekstrak etanol herba binara dengan Metode High Performance Liquid Chromatography (HPLC) (Parhan, 2018).

\section{METODE PENELITIAN}

\section{A. Bahan}

Bahan - bahan yang digunakan dalam penelitian ini adalah ekstrak etanol herba binara (Artemisia Annua), Kloralhidrat, Etanol 96\%, Etil astet, Metanol, Chloroform, n-Heksan, $\mathrm{FeCl}$, pereaksi bourchardat, pereaksi mayer, $\mathrm{NaOH}, \mathrm{H} 2 \mathrm{SO} 4$, Aquadest dan pereaksi Dragendorf.

\section{B. Alat}

Alat - alat yang digunakan dalam penelitian ini adalah Rotary Evaporator(BONE), Hot Plate (VELP AREC), Timbangan neraca analitik (Shimadzu), High Performance Liquid Chromatography (LANSIDA), Plat KLT, Corong pisah (SCHOOT DURAN, Waterbath (MEMMERT).

\section{Pembuatan Ekstrak}

Pembuatan ekstrak etanol dilakukan dengan metode maserasi menggunakan pelarut etanol 96\%. Sebanyak $5 \mathrm{~kg}$ serbuk simplisia dimasukkan kedalam wadah

kaca, lalu ditambahkan pelarut etanol sampai serbuk simplisia terendam, kemudiandidiamkan selama 1 hari lalu ekstrak disaring, setelah itu ekstrak dimaserasi kembalisampai ketika diskrining pada ekstrak tidak terdapat lagi mengandung flavonoid,kemudian diuapkan menggunakan rotary evaporator dengan suhu sekitar $40^{\circ} \mathrm{C}$, hasilnya diperoleh ekstrak kental (Depkes RI, 1979).

\section{Pembuatan Larutan Standar}

Sebanyak 1,25 gram standar yang tersedia dilarutkan dalam $10 \mathrm{ml}$ Metanol $62,5 \%$, sehingga diperoleh standar stock dengan konsentrasi $500 \mu \mathrm{g} / \mathrm{ml}$. Setelah itu $2,5 \mathrm{ml}$ dari standar stock dilarutkan dalam $20 \mathrm{ml}$ Metanol 62,5\%. Kemudian dicampurkandengan $5 \mathrm{ml} \mathrm{HCL} 6 \mathrm{M}$ untukmenjaga kondisi asamnya supaya komponen flavonoid tersebut tidak terdegradasi. Penambahan methanol 
dilakukan hingga volume mencapai $50 \mathrm{ml}$ sehingga konsentrasi yang diperoleh adalah $25 \mu \mathrm{g} / \mathrm{ml}$. Larutan standar yang digunakan dalam penelitian ini terdiri atas lima konsentrasi, yaitu 0.5, $2.5,10,20 \mathrm{dan} 25 \mu \mathrm{g} / \mathrm{ml}$. Sampel yang larut dalam fase gerak diinjeksikan ke dalam kolom kromatografi dengan menggunakan syringe. Volume yang ditampung adalah 0,2 ml, juk berlebih akan dikeluarkan. Fase gerak akan dialirkan dengan menggunakan pompa. Sampel yang masuk kedalam kolom akan didorong oleh fase gerak sehinggazat zat yang terkandung dalam sampel akan dianalisis dan bereaksi dengan fasediam. Oleh detektor akan dibaca dan dihasilkan keluaran berupara grafik dan data tinggi beserta luas puncak dalam bentuk angka.

\section{E. Injeksi Larutan Standar ke kolom HPLC}

Larutan standar dengan berbagai konsentrasi tersebut diinjeksikan kekolom HPLC C-18 phase; Develosil ODS-UG-3 yang memiliki dimensi panjang $75 \mathrm{~mm}$ dan diameter 4,6 mm. Fase gerak yang digunakan adalah $25 \%$ acetonitril didalamKh2PO4 0,025M, dengan laju aliran 0,9 $\mathrm{ml} /$ menit. Diinjeksikan pula larutan standard campuran pada berbagai konsentrasi.

\section{F. Pembuatan Kurva Standar}

Hasil dari kromatogram standar pada berbagai konsentrasi tersebut kemudian dimasukkan kedalam satu grafik. Dari data masing-masing, dibuat persamaangaris yang akan digunakan pada perhitungan Limit of Detection masing-masingstandar. Dari data kromatogram standar campuran, dibuat persamaan garis yangdigunakan pada perhitungan kandungan komponen flavonoid pada sampel.

\section{G. Perhitungan Limit Deteksi}

Limit of Detection (LOD) atau limitdeteksi diperoleh dengan caram enginjeksikannya masing-masing sebanyak standar sebanyak sepuluh kali. Konsentrasi yang digunakan untuk menentukan LOD adalah konsentrasi yang terendah.Setelah diperoleh kesepuluh area tersebut, dimasukkan kedalam persamaan kurva standar masing - masing, sehingga diperoleh konsentrasi dan standard deviasinya. Besarnya LOD adalah tiga kali dari nilai standar deviasi.

\section{H. Teknik Pengumpulan Data dan Analisis Data}

Data yang diperoleh dari hasil penelitian yaitu golongan senyawa metabolitsekunder yang terkandung dalam ekstrak etanol dari hasil skrining fitokimia. Penentuan fasa diam dan eluen dengan menggunakan KLT akan diperoleh data berupa spot - spot hasil pemisahan dan nilai $\mathrm{Rf}$ untuk tiap perbandingan eluen nheksan dan etil asetat, yang selanjutnya hasil pemisahan yang baik untuk menentukan metabolit sekunder.

Pemisahan komponen polar herba binara menggunakan HPLC menghasilkan data berupa profil kromatogram, waktu retensi, dan luas puncak.Jumlah puncak menunjukkan jumlah komponen senyawa dalam ekstrak etanol (kualitatif).Luas puncak digunakan untuk menghitung \% kandungan masing - masing komponen polarsenyawa dalam ekstrak etanol herba binara (kuantitatif).

Dalam proses pemisahan, metode pemisahan yang paling tepat untuk memisahkan komponen polar herba binara adalah metode yang menghasilkan data terbaik dari sisi kualitatif ataupun kuantitatifnya. Komponen polar yang teridentifikasi baik dengan menggunakan metode pemisahan tersebut kemudian dianalisis golongan senyawa lebih lanjut.

\section{HASIL DAN PEMBAHASAN}

18

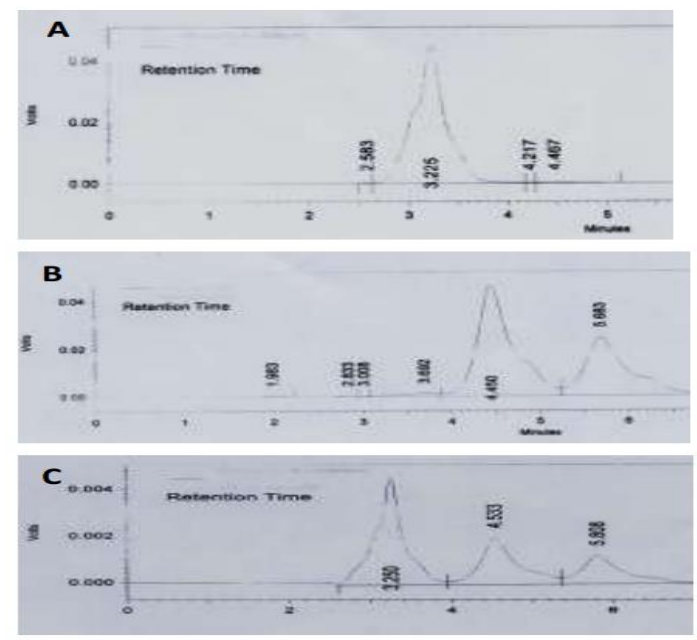


Gambar 4.1 Spektrum Hasil Analisis dengan Menggunakan HPLC (Baku Pembanding.)

Dari beberapa perbandingan fase gerak yang digunakan diperoleh hasil terbaik dengan menggunakan fase gerak chloroform : etil asetat padaperbandingan $7: 3$ dan sistem KCKT partisi fase terbalik RP $18(250 \times 4,6$ $\mathrm{mm}, 5 \mu \mathrm{m})$, detektor UV pada panjang gelombang $360 \mathrm{~nm}$ dan kecepatan alir 1 $\mathrm{mL} /$ menit. Dari kromatogram dapat dilihat bahwa senyawa rutin terlihat pada waktu retensi 3,225 menit, sedangkan pada kromatogram pembanding kuersetin terdapat duapuncak yaitu isokuersitrin terlihat pada waktu retensi 4,450 menit dan kuersetin terlihat pada waktu retensi 5,683 menit. Kromatogram campuran kedua senyawa pembanding tersebut menunjukkan tiga puncak pada waktu retensi 3,250, 4,533 dan 5,808 menit. Pada pengukuran KCKT senyawa pembanding secara berulang diperoleh waktu retensi seperti pada Dari kromatogram hasil pengukuran ekstrak etanol herba binara dapat dilihat bahwa pada fraksi chloroform dan etil asetat dapat terdeteksi beberapa senyawa.

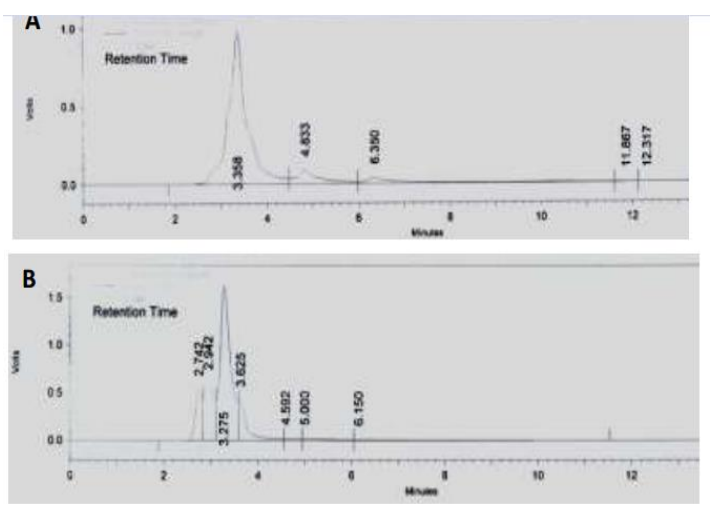

Gambar 4.2 Spektrum Hasil Analisis dengan Menggunakan HPLC (Sampel ekstrak etanol herba binara (Artemisia Annua).

Berdasarkan hasil pengujian pada sampel maka didapatkan kromatogram dari chloroform dan etil asetat. Pada kromatogram fraksi etil asetat dari ekstrak etanol herba binara(Artemisia
Annua) terdapat limapuncak. Pada kromatogram fraksi butanol terdapat tujuh puncak. Bila puncak-puncak yang didapatkan pada kromatogram fraksifraksi dari ekstrak etanol herba binara (Artemisia Annua) dibandingkan dengan waktu retensi senyawa pembanding (Gambar 4.1) terlihat bahwa beberapa puncak mendekati waktu retensi untuk rutin, isokuersitrin dan kuersetin.

Dari hasil penelitian ini dapat dilihat bahwa ekstrak etanol herba binara (Artemisia Annua) memiliki kandungan kimia flavonoid, terutama rutin, isokuersitrin dan kuersetin. Hal ini ditunjukkan dari puncak rutin yang terdapat pada fraksi cloroform dan etil asetat yang lebih dominan sehingga dapat dijadikan sebagai senyawa penanda untuk penentuan mutu ekstrak etanol herba binara (Artemisia Annua). Dengan demikian pola KCKT ini dapat dipakai untuk identifikasi dan pemastian mutu ekstrak etanol herba binara (Artemisia Annua).

\section{KESIMPULAN}

Adapun kesimpulan dari penelitian sebagai berikut :

1. Hasil pemeriksaan golongan senyawa kimia serbuk simplisia herba binara menunjukkan adanya kandungan senyawa kimia seperti alkaloid,flavonoid,saponin, dan tanin.

2. Kadar total flavonoid dalam sample ekstrak etanol herba binara (Artemisia Annua) sebesar 0,93 gram.

3. Dari hasil penelitian ini dapat dilihat bahwa ekstrak etanol herba binara (Artemisia Annua) memiliki kandungan kimia flavonoid yang dilihat dari beberapa puncak yang mendekati waktu retensi baku pembanding yang memiliki kandungan flavonoid yaitu rutin, isokuersitrin dan kuersetin. 
DAFTAR PUSTAKA

Ditjen POM RI.(1979). Farmakope Indonesia. Edisi III. Jakarta:Departemen Kesehatan RI. Halaman 9.

Goodman \& Gilman. (2014). Dasar Farmakologi Terapi. Edisi 10 Volume 2. Jakarta: Penerbit Buku Kedokteran EGC. Halaman 666$675,688-689$.

Katno, Pramono, S.(2005). Tingkat Manfaat dan Keamanan Tanaman Obat dan obat Tradisional. Balai Penelitian Tanaman Obat Tawangmangu Fakultas Farmasi, UGM. Yogyakarta. Http/www.google.com [25 April 2011]. P 1-3

Hariana, Arief.(2013). Tumbuhan Obat dan Khasiatnya Seri I, Jakarta: Penerbit Swedaya Grup

Harborne, J.B. (1987). Metode Fitokimia Penuntun Cara Modren Menganalisa Tumbuhan. Edisi 1. Penerjemah: Kosasih Padmawinata dan Iwang Soediro. Bandung: ITB. Halaman 152.

Lia Febriana. (2017). Obat Tradisional dalam Zaman Teknologi.Majalah Kesehatan Masyarakat No. 56, Hal:3-5.

Marbun, R., Situmorang, N., \& Wahyuni, S. (2018). The efect of immunomodulator by extract ethanol of herba binara (artemisia vulgaris I.) Toward the response of delayed-type hypersensitivity in rat male. Jurnal Penelitian Farmasi \& Herbal, 1(1), 17-21. Retrieved from http://ejournal.delihusada.ac.id/in dex.php/JPFH/article/view/59.

Parhan, P. (2018). Penetapan Kadar NaSiklamat Pada Minuman Serbuk Instan Dan Minuman Kemasan Kaleng Yang Diperdagangkan Di Delitua Dengan Metode Alkalimetri. JURNAL FARMASIMED (JFM), 1(1), 11-15. https://doi.org/10.35451/jfm.v1i1. 88.

Tan, R,X., Zhang, W.F., Tang. (1999). Biologically active substances from the genus artemisia, planta med 64, hal.295-302.

Widyaningrum., Herlina., Tim Solusi Alternatif.(2011). Kitab Tanaman Obat Nusantara. Cetakan Pertama. Yogyakarta: Med Press(Anggota IKAPI). Halaman 209-210.

Yunukawati.(2013). Analisis Senyawa Metabolit Sekunder dari Ekstrak Metanol daun Surian yang berpotensi sebagai Antioksidan. Makara, Sains :48-52. 